\title{
Spectral and Thermal Study of Malonate Crystals Grown by Solution Method
}

\author{
S.P.Shukla ${ }^{1}$, Dr.S.J.Shitole ${ }^{2}$ \\ ${ }^{I}$ Research Scholar R. C. Patel Institute of Technology, Shirpur, \\ ${ }^{2}$ Professor, H R Patel Mahila Mahavidyalaya, Shirpur
}

Received on: 16 July,2021

Revised on: 22 August, 2021

Published on: 24 August, 2021

\begin{abstract}
Crystals of Cadmium malonate have been grown by a simple gel technique using single diffusion method. The optimum growth conditions were established by varying parameters such as $\mathrm{pH}$ of gel solution, gel concentration, gel setting time and concentration of reactants. Good quality of Cadmium malonate crystal was obtained. FTIR are DSC study of these grown crystals is explained.
\end{abstract}

Keywords- Gel growth, Cadmium Malonate, FTIR, DSC.

\section{I- INTRODUCTION}

M etal malonates has a tremendous potential application in molecular electronics, catalysts and biologically active compounds also in supra molecular crystal engineering and molecular based magnetic materials. They are important intermediates in the combination of vitamins $\mathrm{B}_{1}$ and $\mathrm{B}_{6}$, many other pharmaceutics, agro chemicals and flavours. Malonic acid is a dicarboxylic acid and acts as a ligand with different dentate abilities. Its coordination modes depend on the type of synthesis and nature of metal. The crystal structure of malonates is very different from ionic to three-dimension polymers. [1-3]. Previous studies show that precipitation method is widely preferred to grow the malonate crystals [4-7]. While few work has so far been done on growth of metal malonates by gel method. [810]. In this paper, the growth of cadmium malonate crystals by the gel solution method and the results of FTIR and DSC are discussed.

\section{II- EXPERIMENTAL DETAILS}

To obtain the cadmium malonate crystal, solution of sodium metasilicate having a density $1.04 \mathrm{~g} / \mathrm{cc}$ has been prepared. Malonic acid solution of $1 \mathrm{M}$ was added to this, until the mixture attains a $\mathrm{pH}$ value 5. This mixture i.e. gel is allowed for setting in test tube $(15 \mathrm{~mm}$ in diameter, $150 \mathrm{~mm}$ in length) for 36 hours. After gel ageing time up to 72 hours $0.5 \mathrm{M}$ Cadmium Chloride solution was incorporated as upper reactant over set gel. It was observed that Cadmium Chloride solution slowly diffused through the gel reacting with malonic acid already present in medium as inner reactant. After a period of 3 weeks, insoluble cadmium malonate crystals are formed inside the gel and upper side of gel interface as in fig.1. Growth of crystal having size $4 \times 4 \times 3 \mathrm{~mm}^{3}$ was accomplished in the experimental test tube within a period of 5 weeks. Such a crystal can be observed in fig. 2

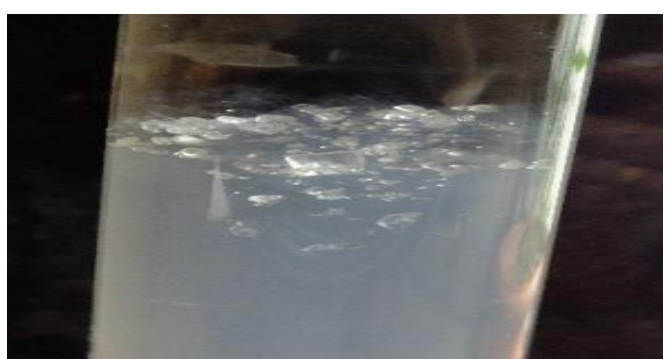

Fig 1-Cadmium Malonate crystals in silica gel 


\section{International Journal of Innovations in Engineering and Science, www.ijies.net}

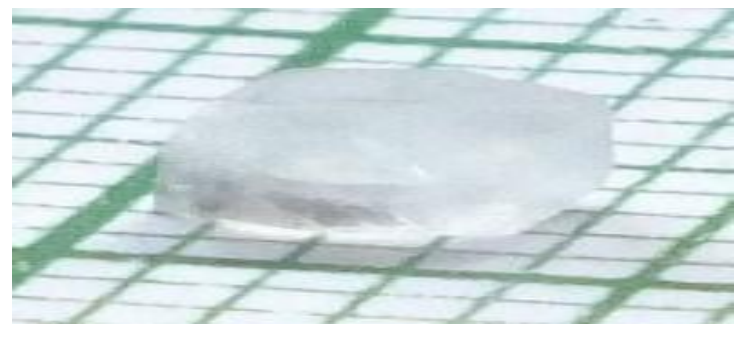

Fig.2- Grown single crystal of Cadmium Malonate.

Reaction used for this is

$\mathrm{H}_{4} \mathrm{C}_{3} \mathrm{O}_{4}+\mathrm{CdCl}_{2}+\mathbf{2} \mathrm{H}_{2} \mathrm{O} \rightarrow \mathrm{CdC}_{3} \mathrm{H}_{2} \mathrm{O}_{4} \cdot 2 \mathrm{H}_{2} \mathrm{O}+2 \mathrm{HCl}$

Optimum growth conditions required to grow good quality of single crystals of Cadmium Malonate are summarized in table 1.

Table 1-Optimum conditions for growth of Cadmium Malonate crystals

\begin{tabular}{|l|l|}
\hline Particulars & Conditions \\
\hline Density of Silica Gel & $1.04 \mathrm{~g} / \mathrm{cc}$ \\
\hline $\mathrm{pH}$ value of gel medium & 5.00 \\
\hline $\begin{array}{l}\text { Concentration of inner } \\
\text { reactant }\end{array}$ & $1 \mathrm{M}$ \\
\hline $\begin{array}{l}\text { Concentration of Outer } \\
\text { reactant }\end{array}$ & $0.5 \mathrm{M}$ \\
\hline Gel Setting Time & 36 Hrs. \\
\hline Gel Ageing time & 72 Hors \\
\hline Growth period & 3 weeks \\
\hline Preferred diffusion method & $\begin{array}{l}\text { Single diffusion } \\
\text { method }\end{array}$ \\
\hline
\end{tabular}

\section{III-RESULT AND DISCUSSION -FTIR}

FTIR spectra of of the prepared sample of Cadmium Malonate is shown in fig. 3

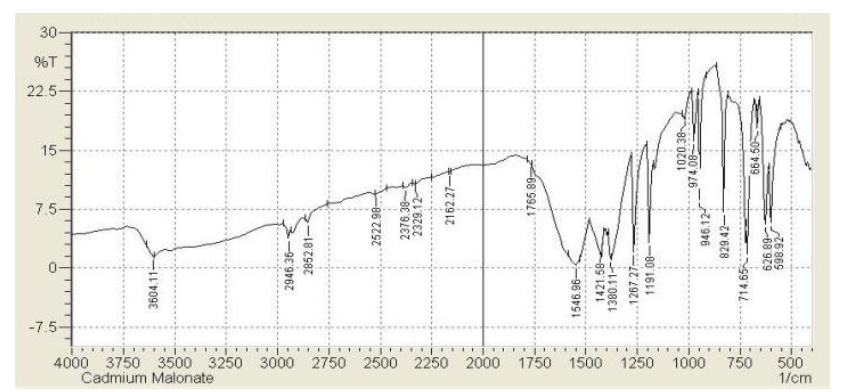

Fig.3- FTIR spectra of Cadmium Malonate

The spectra is interpreted by using the data of related compounds [8-14].The IR spectrum exhibits a broad band assignable to $v(\mathrm{OH})$ of lattice water at $3604.11 \mathrm{~cm}^{-}$
${ }^{1}$.The band in IR spectrum at $2946.36 \mathrm{~cm}^{-1}$ is assigned to $v_{\mathrm{as}}\left(\mathrm{CH}_{2}\right)$ of the methylene group.Six bands observed in the region $2852.81 \mathrm{~cm}^{-1}-1765-89 \mathrm{~cm}^{-1} \quad\left(2852.81 \mathrm{~cm}^{-}\right.$ ${ }^{1}, 2522.98 \mathrm{~cm}^{-1}, 2376.38 \mathrm{~cm}^{-1}, 2329.12 \mathrm{~cm}^{-1}, 2162.27 \mathrm{~cm}^{-}$ ${ }^{1}, 1765.89 \mathrm{~cm}^{-1}$ )are assigned to the patterns of overtones and combinations of various fundamental vibrations in the finger print region. The broad band centered around $1546.96 \mathrm{~cm}^{-1}$ in IR spectrum is assigned to $v_{\text {as }}(\mathrm{OCO})$ and that at $1421.58 \mathrm{~cm}^{-1}$ IR is assigned to $v_{\mathrm{s}}(\mathrm{OCO})$. As two types of carboxylate groups are functionig in this reaction it seems that the IR frequency of $v_{\mathrm{as}}(\mathrm{OCO})$ and $v_{\mathrm{s}}(\mathrm{OCO})$ of the different carboxylate ligands coincides at $1546.96 \mathrm{~cm}^{-1}$ and $1421.58 \mathrm{~cm}^{-1}$ respectively. The difference $\Delta v=\left[v_{\mathrm{as}}(\mathrm{OCO})-v_{\mathrm{s}}(\mathrm{OCO})\right]$ is $125 \mathrm{~cm}^{-1}$.

The strong bonds observed at $1267.27 \mathrm{~cm}^{-1}$ and 1191.08 are assigned to $v_{\mathrm{s}}(\mathrm{C}-\mathrm{O})$ of the two carboxylate groups. The moderate intensity $974.08 \mathrm{~cm}^{-1}$ band in FTIR is assign to deformation mode of $\delta(\mathrm{C}-\mathrm{C})$. The band observed at $946.12 \mathrm{~cm}^{-1}$ in FTIR is assigned to out of plane bending $\delta(\mathrm{C}-\mathrm{H})$. The band observed at $829.42 \mathrm{~cm}^{-1}$ is assigned to out of plane bending $\delta(\mathrm{C}-\mathrm{O})$. The out of plane bending $\delta(\mathrm{CH})$ of methylene group is assigned with the band at $714 . .65 \mathrm{~cm}^{-1}$ band in FTIR. The band observed at $664.5 \mathrm{~cm}^{-1}$ is assigned to rocking mode $\operatorname{\rho r}(\mathrm{C}$ $\mathrm{H})$. The band observed at $626.89 \mathrm{~cm}^{-1}$ in FTIR is assigned to wagging and twisting modes of coordinated water molecule. The band observed at $598.92 \mathrm{~cm}^{-1}$ is assigned to $v_{\mathrm{s}}(\mathrm{Cd}-\mathrm{O})$. The FTIR spectra shows all the characteristic bands expected for the compound[14].

DSC :-

DSC can be used to study the heats of reaction, kinetics, heat capacities, phase transition, thermal stabilities etc. DSC plot is as shown in fig.4

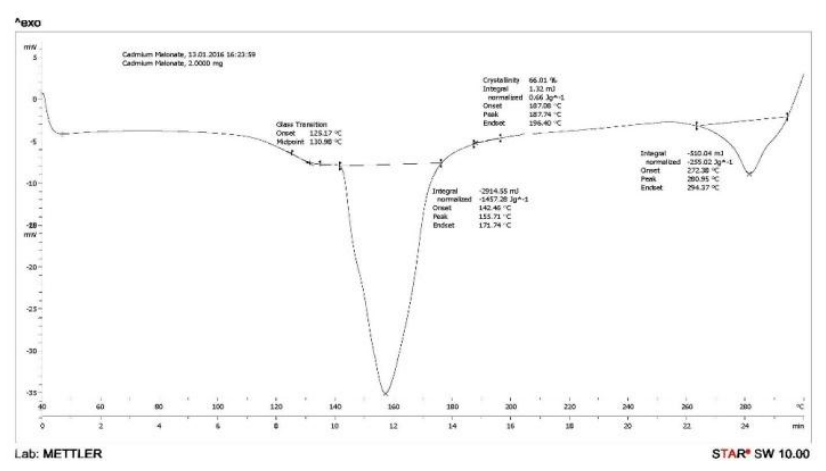

Fig.4- DSC plot of Cadmium Malonate

The DSC plot shows that cadmium malonate has least thermal stability $\left(47^{0} \mathrm{C}\right)$. There are two endothermic 
Vol. 6 , No. 10, 2021, PP. 142-144

International Journal of Innovations in Engineering and Science, www.ijies.net

peaks which detected at $155.71^{\circ} \mathrm{C}, 280.95^{\circ} \mathrm{C}$. These two peaks indicate that cadmium malonate is dihydrate.

\section{IV-CONCLUSION}

Good quality cadmium malonate crystals can be grown in silica gel. Optimum conditons are accomplished. FTIR spectroscopic method is used to successfully used to characterize the grown crystals. FTIR spectra manifest all the characterstic bands expected for the compound. The vibrational study help to explains chelating and bridging coordination associated with the malonate and water molecules. DSC studies show that cadmium malonate is dihydrate.

\section{ACKNOWLEDGMENT}

One of the authors [SPS] thankful to Dr. J. B. Patil, Principal, R. C. Patel Institute of Technology, Shirpur and Dr. P. H. Pawar, Principal, Z. B. Patil College, Dhule for making the laboratory available for research work.

\section{REFERENCES}

[1] Catterick J \& Thornton P, Adv Inorg Chem Radio Chem, 20(1977)291.

[2] Kolenikov V N, Debrovskya M N \& Koreinko V P, Vestn Khar'k Univ,340 (1989) 45.

[3] Yokobayashi H, Nagase K \& Muraishi K, Bull Chem Soc Jpn,48 (1975) 3184

[4] Kazuo Muraishi, Yukihiko Suzuki \& Yukibumi Takahashi, Thermochim Acta,286 (1996) 187.

[5] Bassi P S, Rendhawa R S \& Sandeep Kaur, J Thermal Anal, 35 (1989) 735.

[6] Doreswamy B H, Mahendra M, Sridhar M A et al., Mat Let, 59 (2005)1206.

[7] Varughese P A, Saban KV, George J et al., J Mat Sci, 39 (2004) 6325.

[8] Doreswamy B H, Mahendra M, Sridhar M A et al., Mol Structure, 659 (2003) 81,

[9] Binoy J, Jose P Abraham, Hubert Joe I et al., Raman Spectros, 36 (2005) 63

[10] Brusau E V, Pedregosa J C, Narda G E, Echeverria $G \&$ Punde G, J Solidstate Chem, 153 (2000) 1 .

[11] Deacon G B \& Philips $R$ J, Coordination Chem Rev, 33 (1980) 227.

[12] Varghese Mathew, Jochan Joseph, Sabu Jacob, P A Varughese \& K E Abraham, Indian Journa of Pure \& Applied Physics, Vol.47 October 2009, 691-695. 